\title{
Hidrelétricas no Brasil - da invisibilidade indígena \\ a um licenciamento socioambiental plural
}

Hydroelectric Energy in Brazil - from the indigenous invisibility to a plural environmental licensing

Maria Augusta Assirati ${ }^{1}$

Recebido em 18/01/2016 e aceito em 26/03/2016.

Resumo: O ciclo de energia no Brasil tem sido defendido como sinônimo de desenvolvimento. Empreendimentos hidrelétricos geram inúmeros impactos ao ambiente e às comunidades de seu entorno. NaAmazônia, onde se pretende implementar aproveitamentos hidrelétricos, há forte presença de diversidade sociocultural. A legislação referente aolicenciamento desses empreendimentos, contudo, desconsideraa necessidade de práticas específicas para efetiva garantia da sobrevivência física e cultural dos povos indígenas. Esse artigo avaliaa legislação que orbita em torno do licenciamento ambiental desses empreendimentos e seus efeitos em relação à garantia da vida e dos

1 Maria Augusta Assirati é graduada em Direito. Doutoranda em Direito, Justiça e Cidadania no Centro de Estudos Sociais da Universidade de Coimbra e Mestre em Políticas Públicas pela FIOCRUZ. Presidiu a Fundação Nacional do Índio, onde também exerceu o cargo de Diretora de Promoção ao Desenvolvimento Sustentável. Esteve à frente de outros cargos em órgãos públicos, como o de Diretora na Secretaria-Geral da Presidência da República e o de Coordenadora-geral na Secretaria de Gestão Participativa do Ministério da Saúde. E-mail: guta.assirati@gmail.com 
direitos dos povos indígenas, e a importância de harmonização com outras normas garantidoras de direitos desses povos.

Palavras-chave: povos indígenas; licenciamento socioambiental; hidrelétricas; Amazônia.

Abstract: The energy cycle in Brazil has been advocated as a synonym for development. Hydroelectric projects generate numerous impacts on the environment and the surrounding communities. In the Amazon, where it intends to implement hydroelectric projects, there is a strong presence of social and cultural diversity. The regulations regarding the licensing of these projects, however, disregards the need for specific practices for effective guarantee of the physical and cultural survival of indigenous peoples. This article evaluates the legislation that orbits around the environmental licensing of these developments and their effects in regard to the security of life and the rights of indigenous peoples and the importance of harmonization with other standards guarantors of rights of these peoples.

Keywords: indigenous peoples; licensing; hydroelectric; Amazon.

\section{INTRODUÇÃO}

A demanda por energia no mundo écrescente. As ações ligadas ao incremento da economia brasileira, baseadafundamentalmente na exportação de commodities agrícolas e minerais, são perseguidas como sinônimo de desenvolvimento. Têm, contudo, servido mais à consolidação de perversas consequências do capitalismo, maximizadas pelo fortalecimento do capital financeiro e intensificação do fenômeno da globalização.

Atrelar a promoção de desenvolvimento exclusivamente ao crescimento econômico, ademais, equivale a empobrecer a noção de desenvolvimento. A superação da pobreza, fome e desnutrição, a desconcentração de recursos, a garantia dos direitos fundamentais, a proteção e sustentabilidade da vida ambiental e social, também são desafios ligados ao desenvolvimento.Apenas conjugando elementos 
econômicos, sociais, políticos, ambientais, e culturais, é possível conceber um projeto efetivode desenvolvimento, com base numa concepção contra-hegemônica.

A energia hidroelétrica ocupa lugar de destaque na matriz energética brasileira. Grande parte da energia produzida e consumida no Brasil provém de usinas ou pequenas centrais hidrelétricas que aproveitamáguas dos rios por meio de barragens, gerando impactos diretos e indiretos às comunidades situadas em seu entorno, e ao meio ambiente. Segundo o documento Panorama Energético Nacional: Condicionantes para os investimentos e perspectivas de atendimento do mercado, ${ }^{2}$ apresentado no II Seminário Energia e Meio Ambiente, realizado em Manaus, em junho de 2006:

A matriz energética brasileira está calcada, principalmente, nos derivados de petróleo $(38,4 \%)$, seguido da hidroeletricidade (15\%), cana-de-açúcar $(13,9 \%)$ e madeira e outras biomassas (13,1\%). O gás natural alcança o percentual de $9,3 \%$ e o carvão mineral $6,4 \%$. Além disso, cerca de $45 \%$ da matriz energética brasileira deriva de fontes renováveis. A fonte hidráulica para geração de energia elétrica é considerada a principal vantagem competitiva do Brasil, com grande potencial de expansão. A hidroenergia contribui hoje com $85,4 \%$ da energia elétrica produzida no Brasil e tem um potencial estimado de gerar $260 \mathrm{GW}$. Desse potencial estimado, segundo dados oficiais do Ministério das Minas e Energia, só são aproveitados hoje cerca de $28 \%$ (VERDUM, 2007).

O Plano Decenal de Expansão de Energia 2020 - $\mathrm{PDE}^{3}$ demonstra a elevação da participação da região Norte na expansão de projetos de geração de energia elétrica, passando de 10\%, em 2011, para 23\% da capacidade instalada no sistema, em 2020, totalizando 28.209 MW

2 Disponível em: www.abce.locaweb.com.br/downloads/llseminariomeioambiente/ministro_ nelson_hubner

3 Plano Decenal de Expansão de Energia 2020 / Ministério de Minas e Energia. Empresa de Pesquisa Energética. Brasília: MME/EPE, 2011. Disponível em: http://www.epe.gov.br/ PDEE/20120302_1.pdf 
de expansão. Em contrapartida, nas regiões Sudeste/Centro-Oeste, há uma redução de $60 \%$ para $46 \%$ na participação na oferta total do sistema, mesmo com uma expansão prevista de $12.812 \mathrm{MW}$ para o horizonte decenal. A expansão da potência instalada em todas as regiões agregará $61.560 \mathrm{MW}$ ao SIN, representando um acréscimo de $56 \%$ na oferta de eletricidade.

O governo federal confirma a assertiva, quando anuncia que a "Amazônia está no centro da estratégia de aceleramento do crescimento e de integração do Brasil e com os países vizinhos". Nesse contexto, a sustentabilidade aparece como um elemento que está na ordem dia. "Mas isso, claro, desde que não afete a lógica e o objetivo central do referido sistema: integrar todos os povos e culturas dentro de um sistema capitalista de abrangência mundial"(VERDUM, 2007).

A Bacia Amazônica escoa $20 \%$ do volume de água doce do mun$\mathrm{do}^{4} \mathrm{e}$ a região é fortemente marcada pela presença de comunidades tradicionais, ribeirinhas e indígenas, conformando um cenário repleto de especificidades inerentes ao contexto sociocultural diverso que os caracteriza. Segundo o referido PDE, estão previstos até 2020, doze empreendimentos de geração de energia que interferem em terras indígenas, sendo quatro de interferência direta, e oito de forma indireta. ${ }^{5}$ No campo da transmissão de energia, o plano aponta três empreendimentos com interferência direita, e cinquenta que irão interferir indiretamente em terras indígenas. ${ }^{6}$

Nesse artigo, apontaremos como a legislação referente ao licenciamento ambiental das hidrelétricas e sua implantação, secundarizamo caráter sociocultural dos impactos desses empreendimentos, e desconsideram as especificidades referentes às populações indígenas, dificultando ações voltadas à proteção de sua sobrevivência e à garantia de seusdireitos.

4 Ministério do Meio Ambiente (2009) "Conheça os biomas brasileiros". Disponível em: http://www.brasil.gov.br/meio-ambiente/2009/10/biomas-brasileiros

5 Plano Decenal de Expansão de Energia 2020 - Tabela 180: Indicadores da geração hidroelétrica - página 281. Disponível em: http://www.epe.gov.br/PDEE/20120302_1.pdf

6 Plano Decenal de Expansão de Energia 2020 - Tabela 182: Indicadores da geração hidroelétrica - página 282. Disponível em: http://www.epe.gov.br/PDEE/20120302_1.pdf 


\section{O COMPONENTE AMBIENTAL NO CONJUNTO DE IMPACTOS}

Os ecossistemas ${ }^{7}$ são, via de regra, profundamente modificados pela ação humana. Os empreendimentos hidrelétricos interagem com o meio ambiente, extraindo recursos naturais dos ecossistemas, devolvendo resíduos, e proporcionando significativa alteração do espaço em que atuam.

O desequilíbrio dos ecossistemas descaracteriza e reduz a efetividade dos serviços ecossistêmicos, que são:

[...] benefícios diretos e indiretos obtidos pelo homem a partir dos ecossistemas. Dentre eles pode-se citar a provisão de alimentos, a regulação climática, a formação do solo, etc. São, em última instância, fluxos de materiais, energia e informações derivados dos ecossistemas naturais e cultivados que, combinados com os demais tipo capital (humano, manufaturado e social) produzem o bem-estar humano (ANDRADE e ROMEIRO, 2009).

O equilíbrio ambiental dos ecossistemas e dos serviços que presta é fundamental para a sobrevivência humana. A intervenção humana potencializa sua degradação, alterando o equilíbrio dos fluxos de serviços ecossistêmicos (ANDRADE e ROMEIRO, 2009).

No meio físico, os empreendimentos hidrelétricos provocam, dentre outros impactos, alteração da qualidade do ar, do solo e da água; instalação de processos erosivos; alteração da qualidade das águas; perda de solos com potencial para outros usos; alterações no microclima e nas dinâmicas de escoamento fluvial; perda de lagoas sazonais ou

7 "Sistemas que englobam as complexas, dinâmicas e contínuas interações entre seres vivos e não vivos em seus ambientes físicos e biológicos, nos quais o homem é parte integral" (MA, 2003). "Embora seu conceito seja antigo, o interesse pelos ecossistemas enquanto objeto de pesquisa é relativamente recente, tendo ganhado importância considerável devido à crescente preocupação sobre as interconexões entre o estado dos ecossistemas, o bem-estar das populações humanas e os impactos negativos que mudanças drásticas nos fluxos de serviços essenciais prestados pelos ecossistemas podem ter sobre o bemestar das sociedades." (ANDRADE e ROMEIRO, 2009) 
perenes, pedrais, ilhas, corredeiras.No biótico, acarretam, por exemplo, situações como alteração de comunidadesfitoplanctônicas e zooplanctônicas; floração de bactérias tóxicas; empobrecimento de criadouros naturais;fugae acidentes com a fauna;interrupção ou restrição de fluxos migratórios de peixes e mamíferos aquáticos; proliferação de zoonoses;e redução da ictiofauna.

Segundo a perspectiva da economia política da sustentabilidade, a ação humana relacionada ao atual modelo econômico levará a uma inevitável e completa degradação ambiental, e "o conflito existente entre economia e ecossistemas apenas será resolvido a partir de reestruturação radical da sociedade e de imposição de limites à expansão contínua da produção" (ANDRADE e ROMEIRO, 2009).

Os aproveitamentos hidrelétricos, além de funcionarem como propulsores da produção e do consumo, interferem direta e indiretamente no equilíbrio dos fluxos desses serviços, gerando impactos ao meio físico, biótico, socioeconômico e sociocultural.

\section{O COMPONENTE SOCIOCULTURAL NO CONJUNTO DE IMPACTOS}

O meio social também é fortemente afetado por empreendimentos desse tipo, o que é notável pela interferência nas condições demográficas, atividades produtivas, custo de vida, condições moradia, renda e outras fontes de sustento. Há, ainda, outras decorrências, ligadas ao desordenamento da ocupação territorial, impactosnas condições de saúde, serviços sociais, educação, ao aumento da violência, vulnerabilidade e conflitos sociais. Somam-se, ainda, a depender da caracterização do local do entorno,consequências ao patrimônio histórico, cultural e paisagístico, como alteração ou perda de referências culturais, e comprometimento de bens arqueológicos.

Além dos impactos exclusivamente ambientais,portanto, os aproveitamentos hidrelétricos instauram problemas que afetam direta ou indiretamente os indivíduos e comunidades que vivem em suas proximidades. 
Os instrumentos do processo de licenciamento ambiental de empreendimentos não consideram, como regra, índices relativos a alcoolismo, prostituição, desnutrição infantil, desemprego, mendicância, etc., que aumentam ante a ameaça de implantação desses projetos, que por sua vez, "também têm faces sombrias que necessitam permanente atenção e monitoramento" (SANTOS, 2007).

Buscando equacionar os conflitos relacionados aos impactos, o setor elétrico, como regra, atua orientado por uma lógica puramente economicista, objetiva, e bastante simplificadora. Em regra os empreendedores elaboram cálculos dos prejuízos materiais suportados pela população atingida, e ofertam valores pecuniários às famílias afetadas,a título de indenização, compensação, etc. Para tanto, são considerados parâmetros meramente objetivos, homogeneizadores, causando conflitos sociais expressivos.

Os prejuízos gerados por esses empreendimentos não são meramente materiais ou econômicos. Não há, pois reparação justa, por meio de mera indenização pecuniária. Essas intervenções, comumente, provocam danos graves às comunidades, interferindo em suas histórias de vida, laços comunitários, patrimônios imateriais, organizações sociais, atividades produtivas, modos de sustentação e reprodução física e cultural.

\section{O DIREITO VIGENTE}

Em qualquer processo de licenciamento em que povos e terras indígenas podem ser afetados pela intervenção, aplica-se um conjunto de distintos dispositivos normativos. É impossível tratar juridicamente o tema, no entanto, sem a observância conjunta desses regramentos, sem harmonização entre as diversas normas aplicáveis disponíveis no sistema jurídico. Impõe-se a observação integrada das regras próprias do licenciamento, em harmonia com dispositivos constitucionais, normas oriundas do direito internacional, e princípios que fundamentam o direito indigenista e ambiental no Brasil. Serão a seguir apresentados, alguns dispositivos jurídicos de aplicação relevante nesse campo, e suas implicações na proteção dos povos indígenas. 


\subsection{CONSTITUIÇÃO FEDERAL}

O ponto de partida da análise será a Constituição Federal de 1988, que destinou um rol de direitos específicos aos povos indígenas. $O$ artigo $231^{8}$ reconhece aos indígenas direitos sobre suas terras de ocupação tradicional e o usufruto exclusivo dos recursos naturais ali presentes, limitando a exploração desses recursos por terceiros.

Dispõe expressamente que são nulos e não produzem efeitos jurídicos, os atos voltados à exploração de riquezas naturais das terras indígenas, exceto por motivo de relevante interesse público da União, conforme lei complementar [\$6 $6^{\circ}$.

Portanto, são vedados aproveitamentos hidrelétricos dentro de território indígena. Excepcionalmente, em caso de relevante interesse público da União disposto em lei complementar, fica ressalvada a nulidade do ato. Nessa situação, será exigido o cumprimento das exigências do $\S 3^{\circ}$ do artigo 231. Observadas tais disposições, há impedimento explícito de remover comunidades indígenas de suas terras. Até o presente momento o legislador infraconstitucional não introduziu em nosso ordenamento jurídico, a lei complementar exigida pelo $\S 6^{\circ}$ do artigo 231.

8 "Art. 231. São reconhecidos aos índios [...] os direitos originários sobre as terras que tradicionalmente ocupam, competindo à União demarcá-las, proteger e fazer respeitar todos os seus bens. [...]§ $2^{\circ}$ As terras tradicionalmente ocupadas pelos índios destinam-se a sua posse permanente, cabendo-lhes o usufruto exclusivo das riquezas do solo, dos rios e dos lagos nelas existentes. $\S 3^{\circ} \mathrm{O}$ aproveitamento dos recursos hídricos, incluídos os potenciais energéticos, a pesquisa e a lavra das riquezas minerais em terras indígenas só podem ser efetivados com autorização do Congresso Nacional, ouvidas as comunidades afetadas, ficando-Ihes assegurada participação nos resultados da lavra, na forma da lei. [...] § $5^{\circ}$ É vedada a remoção dos grupos indígenas de suas terras, salvo, "ad referendum" do Congresso Nacional, em caso de catástrofe ou epidemia que ponha em risco sua população, ou no interesse da soberania do País, após deliberação do Congresso Nacional, garantido, em qualquer hipótese, o retorno imediato logo que cesse o risco. § $6^{\circ}$ São nulos e extintos, não produzindo efeitos jurídicos, os atos que tenham por objeto a ocupação, o domínio e a posse das terras a que se refere este artigo, ou a exploração das riquezas naturais do solo, dos rios e dos lagos nelas existentes, ressalvado relevante interesse público da União, segundo o que dispuser lei complementar, não gerando a nulidade e a extinção direito a indenização ou a ações contra a União, salvo, na forma da lei, quanto às benfeitorias derivadas da ocupação de boa fé. [...]" 
A Constituição Federal foi diligente ao impor tal restrição. Pois, um aproveitamento hidrelétrico dentro de terras de ocupação tradicional, equivaleria à geração de impactos irreversíveis gravíssimos à vida das comunidades, ameaçando sua sobrevivência física e cultural, e alterando significativamente a relação cultural, mítica, alimentar, produtiva, ecológica, que estabelecem com os rios.

Boa parte das atividades produtivas desenvolvidas pelas comunidades indígenas é indissociável do manejo dos recursos naturais presentes em seus territórios. Caça, coleta, pesca, agricultura, artesanato, dependem da possibilidade de recorrer a distintos usos de um conjunto de recursos naturais. Ademais, os danos à saúde e as taxas de mortalidade experimentados dentre muitos povos originários na América Latina estão relacionados a fatores de vulnerabilidade socioambiental e territorial, como deslocamentos forçados, escassez de alimentos, contaminação das águas de que se utilizam, degradação dos solos, e desnutrição. ${ }^{9}$ A pressão desses empreendimentos sobre as terras e recursos naturais são intervenções que, como regra, acarretam ou potencializam esses fatores.

Quanto mais próximo da terra indígena o empreendimento, maior seu potencial para gerar impactos dessa natureza. Logicamente, uma intervenção realizada dentro do território atinge o potencial máximo nesse sentido.

Portanto, qualquer ato que pretenda regulamentar a matéria há que ser cauteloso no estabelecimento das exceções e respeitar precisamente os limites definidos pela Lei Maior. As exceções ao impedimento de realizar aproveitamentos hidrelétricos dentro de território indígena devem ser restritas, implicando em situações residuais, já que a Constituição qualifica o interesse apto a excepcionar a regra do usufruto exclusivo.

9 Avances en el último decenio y retos pendientes para la garantia de sus derechos: Documento elaborado pelo Centro Latinoamericano y Caribeño de Demografía (CELADE) - División de Población de la Comisión Económica para América Latina y el Caribe (CEPAL) como parte da preparação da reunião de alto nível - Conferencia Mundial sobre los Pueblos Indígenas em 2014. 
A falta de regulamentação do referido dispositivo não afasta a vedação de exploração hídrica dentro das terras de ocupação tradicional. O suprimento da lacuna apenas definirá precisamente as exceções ao usufruto exclusivo indígena dos recursos naturais existentes em suas terras, e a medida não pode inviabilizar direitos assegurados a esses povos, nem inviabilizar ações que garantam sua reprodução física e cultural.

Qualquer ato normativo que venha a ser instituído com esse intuito deve prever hipóteses limitadas aos casos de comprovada relevância do interesse. Não um interesse ordinário, mas imprescindível, de natureza essencial, que extrapole o âmbito comum da atuação do Poder Executivo. Situações que possam ser solucionadas de outra forma não cabem no conceito de relevante, sob pena de banalizá-lo. O interesse deve ser também público, atribuível indistintamente a toda coletividade, e da União, não sendo as competências estaduais e municipais, aptas para excepcionar a proibição.

No Congresso Nacional tramitam proposições com o fito de regulamentar o referido dispositivo constitucional. ${ }^{10}$ Muitas, contudo, não objetivam a definição de hipóteses que justificam a exploração de recursos naturais em terras indígenas, mas buscam restringir o direito originário dos povos indígenas sobre as suas terras tradicionais, visando dificultar as demarcações. Trata-se de um objetivo impróprio e alheio aos limites estabelecidos constitucionalmente para a regulamentação, motivo pelo qual, quaisquer propostas fundadas nessas bases devem ser rejeitadas de plano.

Outro limite a ser respeitado em caso de regulamentação, refere-se à exploração de recursos e riquezas naturais em áreas com a presença de povos indígenas em situação de isolamento voluntário, vez que a política vigente para proteção dessas populações é a do não conta-

10 O mais emblemático e polêmico projeto a esse respeito é o Projeto de Lei Complementar PLP n 227 de 2012 que regulamenta o $\S 6^{\circ}$ do art. 231, da Constituição Federal de 1988 definindo os bens de relevante interesse público da União para fins de demarcação de Terras Indígenas. 
to ${ }^{11}$. A exploração de recursos nessas áreas é vedada sem qualquer exceção, pois a permissão de exploração nesses casos,impossibilita a proteção desses grupos, colocando em risco sua sobrevivência.

A regulamentação em tela parece requerer uma conceituação geral e abstrata do relevante interesse público da União. A caracterização da situação de fato, ou verificação do atendimento dos requisitos da lei complementar, de outro lado, pode se dar por ato administrativo específico, em cada caso concreto.Por fim, a confirmação do enquadramento do caso concreto na definição da lei complementar, por ato administrativo próprio, deve implicarem dupla afetação do território, evitando que a área de exploração seja excluída dos limites da terra indígena.

Por fim, a proposta de regulamentação e a forma de implementá-la precisam ser objeto de consulta livre, prévia e informada aos povos indígenas. E é devida, ainda, a realização de um amplo debate com os indígenas sobre as complexas questões que envolvem o tema da compensação em caso de eventual exploração de recursos em seus territórios, ainda que em razão de relevante interesse público da União.

\subsection{LEI COMPLEMENTAR No 140 DE 8 DE DEZEMBRO DE 2011:}

A Lei Complementar no 140 de 8 de dezembro de 2011 (LC 140) fixa normas para a cooperação entre União, Estados, Distrito Federal e Municípios,repartindo competências entre os entes federados em matéria ambiental. Seu artigo 7ํatribui à União competência para controlar e fiscalizar atividades e empreendimentos quando o licenciamento

11 Em 1987 teve início a implantação de uma política diferenciada para povos indígenas isolados, denominada "política do não contato", com o objetivo de fazer respeitar seus modos de vida, afastando-se a concepção de obrigatoriedade do contato para sua proteção e os ideários assimilacionistas até então vigentes. Por meio dessa política, o Estado deve reconhecimento e garantia da organização social, costumes, línguas, crenças, territorialidade e tradições dos povos indígenas, a fim de evitar a produção de efeitos colaterais desagregadores provocados pela interferência nas formas de organização social e dinâmicas próprias dessas comunidades. Informações disponíveis em: http://www.funai. gov.br/index.php/nossas-acoes/povos-indigenas-isolados-e-de-recente-contato?start=1\# 
Ihe competir, e, ainda, para promover o licenciamento de empreendimentos localizados ou desenvolvidos em terras indígenas'.

Como já referimos, há vedação constitucional paraexplorar recursosdentro das terras indígenas, não tendo sido definidas até o momento as exceções a essa regra. Por isso, a interpretação da norma deve alcançar também os casos de terras indígenas situadas na área de influência dos empreendimentos.

As terras indígenas abrigam grande parte da biodiversidadeno Brasil. Sua proteção cabe a um único ente federativo, a União. A concentração dessa atribuição na esfera federal visa facilitar ao poder público o desempenho de seus deveres na matéria.Dispersar essa responsabilidade entre os entes federativos, certamente, tornaria mais difícil a proteção dos territórios, a responsabilização do Estado por eventuais omissões, o acesso das comunidades indígenas a políticas e serviços públicos, etc. A finalidade da norma, pois, parece ser a de conferir maior proteção às terras indígenas.

Portanto, não faz sentido interpretar esse dispositivo da LC 140 em sentido literal, limitando sua abrangência a empreendimentos no interior de terras indígenas [vedados, como regra, pela Constituição Federal]. A interpretação literal desviaria o sentido da norma da finalidade que ela pretende alcançar.Assim, a expressão localizados ou desenvolvidos em terras indígenas, utilizada na LC 140, quer significar localizados ou desenvolvidos com geração de impactos em terras indígenas.

Sempre que um projeto hidrelétrico puder afetar terras indígenas, o licenciamento, como regra, deve ser processado pelo órgão ambiental da União, Instituto Brasileiro de Meio Ambiente e dos Recursos Naturais Renováveis (IBAMA).

Ainda que, sob qualquer justificativa,seja delegada a competência para licenciar um empreendimento, em havendo componente indígena, o órgão indigenista federalseguirácompetente para intervir, devendo emitir parecer no processo. Suprimir essa interveniência e prescindir de manifestação sobre o componente indígena, é ignorar os direitos e os riscos a que sesubmetem as comunidades indígenas, produzindo vício no processo. 
Na prática essa competência é delegada sempre que o empreendimento não é de iniciativa federal, mesmo quando há presença de comunidade indígena na área de influência. Isso gera sensível prejuízo às comunidades afetadas, que acabam por suportar a desconsideração de seus direitos, ou o despreparo estadual para tratar suas questões.

Outro fator relevante a ser destacado no tocante a esse aspecto é que:

Se no plano federal há uma relativa transparência e controle social, é nos planos estadual e, principalmente, municipal onde estão postos os principais desafios para a efetivação do controle social sobre o processo de licenciamento ambiental, e mesmo assim fortemente influenciado pela pressão econômica e pelas estratégias clientelistas associadas (VERDUM, 2007).

\subsection{PORTARIA INTERMINISTERIAL N 60 DE 24 DE MARÇO DE 2015:}

Firmada pelos Ministros de Estado do Meio Ambiente, Justiça, Cultura e Saúde, a Portaria Interministerial no 60 de $2015^{12}$ estabelece procedimentos administrativos que disciplinam a atuação dos órgãos e entidades da administração pública federal em processos de licenciamento ambiental, dentre os quais, a Fundação Nacional do Índio (FUNAI). ${ }^{13}$

O instrumento impõe uma série de dificuldades à proteção dos direitos indígenas no licenciamento de empreendimentos que os afetam, inclusive hidrelétricos.

12 O referido instrumento revogou expressamente e sucedeu a Portaria Interministerial no 419, de 26 de outubro de 2011, que atuava em parâmetros semelhantes.

13 Autarquia vinculada ao Ministério da Justiça, responsável pela coordenação da política indigenista em âmbito nacional. Possui, dentre suas competências, a atribuição de intervir nos processos de licenciamento ambiental para garantir o cumprimento dos direitos de povos e comunidades indígenas que se encontram na área de influência do empreendimento a ser licenciado. 
Determina que os órgãos e entidades envolvidos no licenciamento ambiental federal apresentem ao IBAMA manifestações sobre o estudo ambiental realizado e sobre o programa de mitigação e controle de impactos apresentado. A FUNAImanifesta-se sobre os impactos a que se sujeitam os povos e terras indígenas de acordo com o projeto de empreendimento,e sobre as medidas propostas para seu controle e mitigação.

No caso de aproveitamentos hidrelétricos, o Anexo I da Portaria considera influenciadas pelos empreendimentos, terras situadas no raio dequarenta quilômetros para intervenções na Amazônia Legal, ${ }^{14}$ ede quinze quilômetrosnas demais regiões do país, medidasas distâncias a partir do eixo do barramento.

Delimitar a região de influência dos empreendimentos equivale a eleger as áreas, e portanto, comunidades que farão jus a estudos de impacto ambiental, e a ações mitigadorase/ou compensatórias dos impactos provocados. O critério adotado pela Portaria [distância entre o barramento e a área afetada é, entretanto, absolutamente impróprio para tanto.Leva a uma discriminação objetiva e simplificadora. Ora, uma comunidade distante quarenta e um quilômetros do barramento, sujeita-se, por exemplo,às mesmas alterações dos regimes de cheia e vazante do rio, dificuldades de transposição do rio, ou modificação da qualidade da água, sofridas pelas comunidades situadas a quarenta quilômetros.

As hidrelétricas não atingem somente o ambiente, mas indivíduos e comunidades. Por issoexigematuação de caráter socioambiental. Os efeitos negativospodem atingir mesmo aquelas que estejam fora da faixa de proteção normativa.Portanto, tudo que as afetadeve ser objeto de atenção por parte dos empreendedores e do Estado.

A Portaria se equivoca ao excluir certos grupos da proteção jurídica, recorrendo para tanto, ademais, a um critério [distância entre o barramento e o território] que, por sua objetividade é incompatí-

14 Amazônia Legal: região administrativa instituída no Brasil por meio de atos normativos das décadas de 1950 e 1960, e que abrange, atualmente, nove Estados da Federação com territórios, total ou parcialmente, caracterizados pela vegetação e hidrografia amazônicas. 
vel com a proteção das populações do entorno. É inadmissível que uma comunidade seja excluída do rol das afetadas por tal razão, e permaneça fora do círculo das preocupações do Estado e do empreendedor. Todos os impactos advindos da intervenção devem considerados para avaliar a viabilidade do empreendimento, e tratados no caso desua implementação.

O mesmo dispositivo da Portaria prioriza, ainda, a proteção do bioma amazônico em relação aos demais.

A Amazônia é a maior reserva de biodiversidade do mundo e o maior bioma do Brasil, ocupando quase metade [49,29\%] do território nacional. Estima-se que abrigue mais da metade de todas as espécies vivas do Brasil. ${ }^{15}$ Justifica-se, pois,um alto nível de proteção de seus recursos. O que não se justifica é a proteção reduzida emáreas situadas nos demais biomas. Estãono Cerrado as nascentes das três maiores bacias da América do Sul [Amazônica/Tocantins, São Francisco e Prata], com elevado potencial aquífero e abrigo de mais de 6.500 espécies de plantas já catalogadas. A Mata Atlântica, tendo sido um dos mais ricos e variados conjuntos florestais da América do Sul, é hoje o bioma brasileiro mais descaracterizado, em razão dos primeiros episódios de colonização e dos ciclos de intervenção econômica que destruíram grande parte desses ativos. A Caatinga, exclusivamente brasileira,é o principal bioma da Região Nordeste, e apresenta grande riqueza de ambientes e espécies não encontradas em nenhum outro bioma. O Pantanal, praticamente exclusivo do Brasil, e o Pampa, ofertam igualmente grande riqueza em biodiversidade. ${ }^{16}$

Reduzir a proteção das áreas situadas nos biomas não amazônicos é um equívoco sob o aspecto ambiental, pois se encontram em pior estado de conservação.

15 Ministério do Meio Ambiente (2009) "Conheça os biomas brasileiros": http://www.brasil. gov.br/meio-ambiente/2009/10/biomas-brasileiros

16 Ministério do Meio Ambiente (2009) "Conheça os biomas brasileiros":http://www.brasil. gov.br/meio-ambiente/2009/10/biomas-brasileiros 
Quando um serviço ecossistêmico é abundante em relação à sua demanda, um incremento marginal em seu fluxo representa apenas uma pequena contribuição ao bem-estar humano. Entretanto, quando o serviço ecossistêmico é relativamente escasso, um decréscimo em seu fluxo pode reduzir substancialmente o bem-estar (ANDRADE e ROMEIRO, 2009).

De outro lado, a distinção entre os biomas expressa, mais uma vez, a prevalência da proteção ambiental em detrimento do cuidado com os prejuízos sociais associados a esses projetos. Mesmo nos casos de instalação de hidrelétricas fora da Amazônia Legal, as comunidades indígenassão igualmente expostas ao risco de impactos, o que exige idêntica proteção jurídica.

Finalmente, a referida Portariarestringe o conceito de terra indígena. Compreende-ascomo asáreas ocupadas por povos indígenas que tenham sido identificadas e delimitadas por meio de relatório publicado no Diário Oficial da União, ou interditadas em razão da localização de índios isolados, por portaria publicada no mesmo veículo, ou caracterizadas por qualquer modalidade prevista no artigo 17 da Lei $n^{\circ} 6.001$ de 19 de dezembro de $1973 .{ }^{17} \mathrm{O}$ estudo; a publicação do relatório circunstanciado de identificação e delimitação; o contraditório administrativo; a declaração; a homologação; e a regularização, constituem etapas do processo administrativo demarcatório de terras indígenas. ${ }^{18}$

17 O artigo 17 da Lei $n^{\circ} 6.001$ de 1973 dispõe que: "Reputam-se terras indígenas: I - as terras ocupadas ou habitadas pelos silvícolas, a que se referem os artigos $4^{\circ}$, IV, e 198, da Constituição; II - as áreas reservadas de que trata o Capítulo III deste Título; III - as terras de domínio das comunidades indígenas ou de silvícolas." Os dispositivos constitucionais (artigos $4^{\circ}$ e 198) constavam, respectivamente, das Cartas de 1967 e sua Emenda $n^{\circ}$ 1 de 1969, ab-rogadas pela Constituição de 1988. Portanto, a Portaria Interministerial $n^{\circ} 60$ de 2015, ao referir-se a hipóteses previstas na Lei 6001/73, abrange apenas os casos de reservas indígenas, que ficam incluídas no rol de áreas protegidas no âmbito do licenciamento ambiental.

18 Os procedimentos administrativos para demarcação de terras indígenas são estabelecidos pelos seguintes diplomas: Decreto n. ${ }^{\circ} 1775 / 96$, que dispõe sobre o procedimento administrativo de demarcação de terras indígenas; Portaria Ministério da Justiça n 14/96, que estabelece regras sobre a elaboração do relatório circunstanciado de identificação e delimitação de terras indígenas; e Portaria Ministério da Justiça $n^{\circ}$ 2498/11, que regulamenta a participação dos entes federados no âmbito do processo administrativo de demarcação de terras indígenas. 
A norma quis incluir no espectro dolicenciamento ambiental, apenas as áreas indígenas que cumpram aqueles determinados requisitos formais. As terrasque não cumpram a formalidade citada, mesmo impactadas, ficam excluídas da proteção jurídica nos licenciamentos de empreendimentos.

Nesses casos, o empreendedor não tem obrigação de realizar estudos de impacto, nem de apresentar programas de mitigação ou compensação de impactos. Ou seja, ainda que o aproveitamento hidrelétrico acarrete prejuízos acomunidades indígenas em terras não enquadradas nas hipóteses da Portaria, o empreendedor, no processo de licenciamento,não terá responsabilidade pelas consequências de sua intervenção. Se dentro da área de influência definida pela Portaria $n^{\circ} 60$, se deparar com indígenas em terras ainda não identificadas e delimitadas, goza de amparo da Portaria para ignorar a presença indígena, pois nenhuma providência lhe será exigida nesse caso.

Consequentemente, a FUNAI somente podeintervir no processo e manifestar-se sobre os impactos e direitos indígenas, nos casos que envolvem terras enquadradas nas hipóteses da Portaria.

A ocupação das terras tradicionais é direito originário dos povos indígenas. À União, por dever constitucionalmente estabelecido, compete demarcar e proteger esses territórios. A demarcação não se reveste de natureza constitutiva, mas meramente declaratória. Não há, pois, razão para excluiras terras indígenas não demarcadas.

O artigo 67 do Ato das Disposições Constitucionais Transitórias da Constituição da Repúblicaconferiu à União prazo de cincoanos a partir de 1988para concluir a demarcação das terras indígenas.

A tarefa não foi concluída no prazo estabelecido, e o Estado aindadevea reparação territorial a muitos desses povos. Por diversas razões, há um contingente de terras indígenas ainda não reconhecidas. Mas, uma vez que a falta de reconhecimento administrativo não descaracterizaa ocupação tradicional, não há razão para que o licenciamento exclua da proteção jurídica as terras indígenas que ainda não foram formalmente reconhecidas. Trata-se de mais uma discriminação equivocada, que submete algumas comunidades indígenas a um pre- 
juízo indevido,em razão da morano cumprimento das obrigações de órgãos do próprio Estado.

Aregra produz uma iniquidade no tratamento de grupos indígenas que vivem emterras que,embora igualmente indígenas esujeitas a idênticas consequências do empreendimento, situam-se em etapas distintas do processo demarcatório. A normafere outros dispositivos do ordenamento jurídico vigente, inclusive constitucionais, merecendo reforma.

\subsection{PARTICIPAÇÃO INDÍGENA}

Ao abordar o tema dos empreendimentos hidrelétricos, diversos princípios poderiam ser invocados como proposições centrais no condicionamento da participação dos povos indígenas. Um deles é o Princípio da Participação, por enfatizar a necessidade e a relevância da cooperação entre setores da sociedade na gestão das questões de proteção ambiental.

É viável e imprescindível a participação plena das comunidades indígenas na tomada de decisões e nas ações referentes aos aproveitamentos hidrelétricos, sempre que a intervenção possainfluenciar suas vidas.

Aproveitamentos hidrelétricos afetam recursos de usufruto exclusivo indígena, indispensáveis a sua sobrevivência física e cultural. Eventual mitigação desse direito demanda o estabelecimento de um consenso comseus titulares. Ademais,o exercício da participação social expressa um preceitofundamental da democracia.Portanto, é indispensável que os indígenas participem das decisões e ações sobre esses empreendimentos.

O Princípio da Participaçãonesse tema é expresso em diversas normas. A Constituição Federal, no artigo 225, determina "ao Poder Público e à coletividade o dever de defender e preservar o meio ambiente para as presentes e futuras gerações". A Declaração do Rio sobre Meio Ambiente e Desenvolvimento de 1992 refere-se expressamente à participação popular na proteção do meio ambiente, ressaltando 
que "a melhor maneira de tratar as questões ambientais é assegurar a participação, no nível apropriado, de todos os cidadãos interessados."

O direito à participação pressupõe o direito à informação, pois é a partir deste que os grupos sociais reúnem condições para efetivar sua participação. No licenciamento de empreendimentos é imprescindível que o poder público compartilhe adequadamente todas informações, sobretudo com as comunidades potencialmente afetadas pela intervenção. O pleno acesso à informação proporcionao acesso amecanismos administrativos e/ou judiciais de defesa de direitos, inclusive quanto à mitigação, reparação, ou compensação de danos.

O exercício do direito à participação e à informação nolicenciamento de empreendimentosconta com previsões específicas.

A Resolução 001/86 do Conselho Nacional do Meio Ambiente (CONAMA ${ }^{19}$ dispõe que o licenciador abrirá prazo para receber comentários sobre o estudo e relatório de impacto ambiental e, sempre que julgar necessário, realizará audiência pública para informação sobre o projeto e seus impactos ambientais. Como a sociedade civil compõe o CONAMA, inferem-se desses dispositivos duas formas de participação popular: uma pela representação no Conselho, e outra pelas audiências públicas. São mecanismos ainda insuficientes e, na prática, implementados de modo muito tímido, possibilitando pouca influência nas decisões tomadas sobre os projetos.

Em se tratando de povos indígenas, entretanto, para assegurar o cumprimento do direito à participação é preciso observar, sobretudo, as previsões da Convenção $n^{\circ} 169$ da Organização Internacional do Trabalho (OIT), uma vez que esse instrumento refere-se especificamente aos povos indígenas.

\subsubsection{CONVENÇÃO N 169 DA OIT}

A Convenção $n^{\circ} 169$ da OIT sobre povos indígenas e tribais é adotada pelo Brasil, onde foi promulgada pelo Decreto $n^{\circ} 5051$ de 19 de

19 Previsão do artigo $11 \S 2^{\circ}$ da Resolução 001/86. 
abril de 2004, reconhecendo as aspirações desses povos a assumir com autonomia e autodeterminação, o controle de suas instituições, formas de vida e desenvolvimento, e a manutenção e fortalecimento de suas identidades, línguas e crenças. $O$ instrumento observa que esses povos são, muitas vezes, privados de gozar de direitos humanos fundamentais, e enfatiza sua especial contribuição à diversidade cultural, e harmonia social e ambiental, estabelecendo uma série de medidas a serem observadas e implementadas em prol da garantia de sua sobrevivência física e cultural. Assegura aos povos indígenas, em seu $6^{\circ}$ artigo, ${ }^{20}$ o direito a serem consultados sobre medidas passíveis de afetá-los, assegurando no artigo $7^{\circ}$ sua autodeterminação, ao garantir sua decisão, participação, ou cooperação em todos os assuntos que se relacionam com suas vidas.

A Convenção traz diversos elementos que fundamentam um tratamento específico em relação aos povos originários, bem como determina aos governos o cumprimento de certas medidas específicas sempre que a realização de atividades possa interferir na organização social, política, ou cultural de qualquer comunidade indígena.

Quaisquer que sejam as formas de participação das comunidades indígenas nas decisões sobre esses empreendimentos, a realização de um processo de consulta que cumpra os requisitos da Convenção 169 da OIT, jamais poderá ser dispensada. A consulta é, por excelência, o meio para estabelecer-se o diálogo com essas populações.

A Convenção 169, bem como a Declaração das Nações Unidas sobre os Direitos dos Povos Indígenas, incorporam a dimensão coletiva da participação desses povos nos assuntos que os envolvem. Preconizam a adoção de formas de participação que afirmem a auto-

20 "1. Na aplicação das disposições da presente Convenção, os governos deverão: a) consultar os povos interessados, por meio de procedimentos adequados e, em particular, de suas instituições representativas, sempre que sejam previstas medidas legislativas ou administrativas suscetíveis de afetá-los diretamente; b) criar meios pelos quais esses povos possam participar livremente, ou pelo menos na mesma medida assegurada aos demais cidadãos, em todos os níveis decisórios de instituições eletivas ou órgãos administrativos responsáveis por políticas e programas que lhes afetem; c) estabelecer meios adequados para o pleno desenvolvimento das instituições e iniciativas próprias desses povos e, quando necessário, disponibilizar os recursos necessários para esse fim." 
nomia e a autodeterminação dos povos indígenas, além de preservar e reforçar suas próprias instituições políticas, jurídicas, econômicas, sociais, e culturais. ${ }^{21}$

Por isso, o modelo que esses instrumentos definem para o exercício participativo a ser desempenhado, justamente em função das especificidadesculturais indígenas, se diferencia do desenho convencional da participação exercida pelos demais segmentos sociais.

Esse direito dever, pois, ser aplicado por meio da realização de consulta livre, prévia, e informada às comunidades envolvidas.

No Brasil, essa consulta determinada pela norma, tem sido objeto de grande discussão. O Governo Federal vem discutindo e propondo uma regulamentação da Convençãoa fim de estabelecer e uniformizar procedimentos para a realização da consulta. Esses debates têm circulado em torno de pontos fundamentais no processo de modelagem das consultas. Dente eles figuram, a definição de competência para concretizar os atos da consulta, e o caráter (deliberativo ou não) do resultado da consulta, os quais se encontram aqui em destaque, por constituírem razões centrais adotadas pelo Governo Federal para fundamentar o argumento da dúvida sobre a forma de concretizar esse direito.

Defendo que os processos de consulta devem ser planejados, coordenados, e contar com participação protagonista de atores estatais que integram o governo, em cooperação com lideranças indígenas do povo a ser consultado. Os recursos para realização das atividades devem ser suportados por órgãos do Estado. Dessa forma, o estabelecimento de consensos intragovernamentais para definir os órgãos que podem compor o grupo de governo que será responsável por tal atribuição, não representa tarefa tão difícil, e sob nenhum argumento, um desafio intransponível.

21 Avances en el último decenio y retos pendientes para la garantia de sus derechos: Documento elaborado pelo Centro Latinoamericano y Caribeño de Demografía (CELADE) - División de Población de la Comisión Económica para América Latina y el Caribe (CEPAL) como parte da preparação da reunião de alto nível - Conferencia Mundial sobre los Pueblos Indígenas em 2014. 
Conforme o procedimento atualmente adotado para a realização dos licenciamentos ambientais federais, o IBAMA não desenvolve qualquer ação em relação à consulta determinada pela Convenção 169. Em razão disso, a implementação de medidas voltadas ao cumprimento de suas determinações vem sendo buscada fora do processo de licenciamento dosempreendimentos (inclusive hidrelétricos). Em alguns casos, a exemplo do que se deu no caso da UHE Belo Monte, os processos de consulta são operacionalizados e financiados pelos empreendedores. Essa não é uma alternativa acertada, pois os interesses das empresas empreendedoras, como regra,não convergem com a garantiade que os indígenas possam efetivamente interferir nas decisões.

Quanto aos efeitos da consulta:

[...] tópico que suscita as maiores controvérsias, há aqueles quedefendem ser a consulta mera formalidade, sem aptidão para interferir no processo decisóriodo Estado, e há outros que advogam a possibilidade incondicional de veto ao projeto.Ambas as posições, contudo, parecem equivocadas. A primeira, por ignorar os próprios pressupostos e requisitos que a Convenção 169 estabelece para a consulta, acima enunciados. E a segunda, por desconsiderar que, numa sociedade plural, nenhum grupo pode ter o domínio absoluto das decisões que escapam ao seu exclusivo interesse (DUPRAT, 2014).

Em relação a medidas como a implementação de uma ação, obra, ou política pública dentro de seu território, que lhe diz respeito com exclusividade, a decisão da comunidade indígena equivale à anuência ou óbice, e deve ser vinculante, pois representa uma decorrência da autodeterminação do grupo, da autonomia na estipulação e gerência de seus projetos de desenvolvimento (DUPRAT, 2014). Nos demais casos, o processo servirá à construção conjunta e pactuação de consensos, e seus resultados devem ser incorporados aos processos decisórios, sendo indissociáveis das ações a serem adotadas visando a desistência ou não realização, o prosseguimento, ou a reformulação dequalquer aspecto, dos projetos e obras hidrelétricas submetidos à consulta. 
Conforme pondera Azelene Kaingang, socióloga e integrante do Instituto Indígena Brasileiro Warã: "É preciso definir o que é o consentimento prévio, livre e informado dos povos indígenas para as ações que os afetam. Uma consulta não é apenas a oportunidade de dizer sim ou não para determinado empreendimento, mas a possibilidade de abrir o diálogo entre o Estado e os povos indígenas e finalmente se definir os interesses de cada um e estabelecer uma relação de respeito mútuo" (BANIWA, 2012).

Esses debatestêm tornado tímida a realização da consulta na prática.É possível que a regulamentação do dispositivo da Convenção possa contribuir na definição das competências, na devida alocação de recursos públicos para o cumprimento do dever, que é do Estado, e no estabelecimento mais preciso acerca da incorporação dos efeitos da consulta.

Em hipótese alguma, contudo, a falta de regulamentação da matéria pode ser invocada como argumento para justificar o descumprimento da Convenção 169, tendo em vista o caráter de observância obrigatória e aplicabilidade imediata de seus dispositivos, já que constituem direitos fundamentais. Conforme sustentam diversos juristas, os tratados internacionais de proteção dos direitos humanos incorporados pelo ordenamento jurídico brasileiro possuem natureza materialmente constitucional, em razão do que dispõe o $\S 2^{\circ}$ do art. $5^{\circ}$ da Constituição Federal - "os direitos e garantias expressos nesta Constituição não excluem outros decorrentes do regime e dos princípios por ela adotados, ou dos tratados internacionais em que a República Federativa do Brasil seja parte" -, bem como por interpretação embasada no princípio da máxima efetividade dos direitos fundamentais (PIOVESAN, 2013).

Fundamental nesse processo é a certeza de que a participação indígena seja efetiva, por meio de um processo de consulta que observe as disposições legais,e sobretudo, a necessidade de consideração das especificidades culturais envolvidas. Estabelecida essa premissa, a arquitetura institucional utilizada para implementá-la pode assumir variadas formas que atendam as necessidades e possibilidades dos grupos consultados, procurando minimizar a assimetria comumente 
determinante dessa relação. São requisitos imprescindíveis, boa-fé, liberdade, e compartilhamento justo de informações entre as partes, e a realização prévia às decisões que envolvem o projeto. Esse processo participativo deve significar e resultar no compartilhamento de poder na tomada de decisões, já que estas não dizem respeito exclusivamente ao Estado, produzindo efeitos que interferem nas condições físicas e/ou culturais da vida de povos e comunidades indígenas.

\section{O DIREITO VIGENTE E OS POVOS INDÍGENAS}

As normas estabelecidas no âmbito do licenciamento desses projetos, como se nota, não possuem elementos aptos a tratar as especificidades das comunidades indígenas afetadas, motivo pelo qual, não as contemplam em suas necessidades. Essa legislação foi concebida com base nos pilares monoculturais que embasam a produção de todo o direito, como regra. De outro lado, seria possível ajustar esse desvio no momento da aplicação dessas normas, conjugando-as com as previsões indigenistas vigentes, instituídas pela Constituição Federal e pela Convenção 169 da OIT, por exemplo. No entanto, os atuais e notórios conflitos envolvendo indígenas no que tange às hidrelétricas, demonstram que esse esforço não vem sendo empreendido pelos gestores e operadores dos setores elétrico, ambiental e de infraestrutura.

Avançar nesse sentido exige que sejam transpostos os paradigmas monoculturais que conformam a relação do Estado com os povos indígenas, realçando o multiculturalismo, não só como um dado da realidade, mas como uma maneira de intervir e transformar a dinâmica social, trabalhando as relações culturais para conceber políticas públicas nessa direção (CANDAU, 2008).

Esse multiculturalismo crítico, ou interculturalidade, ${ }^{22}$ assume as relações culturais como vínculos permeados por mecanismos de poder, e rejeita a ideia da cultura como não-conflitiva. Mas também projeta

22 A abordagem adotada aproxima-se do multiculturalismo crítico, ou multiculturalismo de resistência de Peter McLaren (1997). 
transformações a partir de uma agenda de valorização da diferença "dentro de uma política de crítica e compromisso com a justiça social" (CANDAU, 2008).

Desses campos de luta, instaurados a partir de projetos de infraestrutura, emergem linguagens diferentes na avaliação dos valores envolvidos. Neles se dá o confronto entre variáveis como lucros, vantagens econômicas, e recursos que sustentam o "metabolismo social das economias industriais" (MARTINEZ-ALIER, 2014), e valores como os direitos humanos à vida e à saúde, o caráter sagrado da terra, e os direitos territoriais indígenas. São conflitos que não giram apenas em torno de questões ligadas à distribuição, mas de consequências e circunstâncias e referentes à adoção ou à negação do reconhecimento e da diversidade e participação.

Nesse sentido, Boaventura de Sousa Santos sugere que os problemas criados pela monocultura sejam enfrentados por meio de um diálogo a que se refere como hermenêutica diatópica, como um caminho para que os direitos humanos possam interagir e interferir socialmente de forma contra-hegemônica, por meio da prática sistemática da interculturalidade nos processos de manejo desses direitos (SANTOS, 2009).

Na mesma trilha, os vetores "descolonización epistémica; alternativas al "desarrollo" y Buen Vivir; transiciones al postextractivismo; crisis civilizatoria y alternativas a la modernidad; y la lógica de lo comunal, la relacionalidad, y el pluriverso", são tidos como os eixos emergentes na construção de um novo e diferente cenário de pensamentos, estudos, e processos políticos e culturais, confrontando o que têm prevalecido ultimamente (ESCOBAR, 2014).

No tema ora discutido, a opção política pelo estabelecimento de relações interculturais nesses moldes conduziria o Estado, possivelmente, a reconhecer a inviabilidade de uma série de projetos hidrelétricos próximos a comunidades indígenas.

Todavia, o que temos constatado é o prosseguimento desses projetos e obras, com desconsideração dessas variáveis socioculturais. Sobre esses empreendimentos é possível afirmar: 
Ainda, que independentemente do matiz ideológico que os esteja orientando no processo de planejamento, o que se observa e constata é que eles têm sido, inequivocamente, formas de produção vinculadas a um sistema econômico caracterizado pela produção e reprodução ampliada de capital. Um sistema orientado pelo paradigma (hegemônico) de integração de todos os povos e culturas dentro de um sistema capitalista de abrangência mundial (VERDUM, 2007).

Trata-se da concretização de um projeto de desenvolvimento [hegemônico] gerado com base em valores que orbitam em torno de um elemento apenas: o econômico. Por isso, um desenvolvimento incompleto, ineficaz para diversos setores da sociedade, em especial para populações culturalmente diversas.

Ao que parece, estamos vivenciando a reprodução de idéias e práticas (recauchutadas) do velho modelo de desenvolvimento, no qual as grandes obras de infra-estrutura são os principais vetores de promoção e indução de expansão da fronteira (frontier) política e econômica do capitalismo (privado e estatal), para regiões até então relativamente isoladas ("marginais"), e da redefinição de formas de ocupação e exploração de territórios que no passado foram objeto de projetos de desenvolvimento ou de modernização de processos produtivos (VERDUM, 2007).

O direito acompanha, sustenta e legitima esse modelo socioeconômico, e portanto, as normas que regulam o planejamento e implantação desses empreendimento, são incompatíveis com a defesa efetiva dos direitos indígenas ante tais intervenções.

\section{O CARÁTER SOCIOAMBIENTAL NO DEBATE}

A garantia dos direitos dos povos originários, incluindo-se a livre expressão de seus modos tradicionais de vida e a proteção de seus territórios, vincula-se à proteção ambiental. Grande parte das cosmo- 
visões indígenas concebe a terra, a natureza, e o Homemdentro de um conjunto indissociável de elementos da vida.

Como os recursos naturais compõem as relações de identificação desses povos com seus territórios tradicionais, seu compromisso para com a proteção territorial e ambiental é, geralmente, elevado. $\mathrm{E}$ os modos particulares pelos quais, comumente, desenvolvem a exploração desses recursos, baseados no respeito e proteção, e em conhecimentos tradicionais sobre seu manejo, expressam um sentido de sustentabilidade.

As terras indígenas apresentam o menor índice de desmatamento da Amazônia Legal, com um índice médio de apenas $1 \%$ no total de desmatamento da região, contra59\% verificado em áreas privadas. Setenta e cinco por cento das terras indígenas mais desmatadas localizam-se em áreas que apresentam alguma vulnerabilidade específica, como empreendimentos de infraestrutura, demora na regularização fundiária, discussões judiciais, ou presença não-indígena. O Instituto Nacional de Pesquisas Espaciais constatou que $57 \%$ da floresta remanescente na Amazônia Legal localiza-se em Terras Indígenas e Unidades de Conservação. ${ }^{23}$

Embora a utilização racional de recursos naturais não se circunscrevaao âmbito das práticas indígenas, os fatores acima aduzidos configuram razões fortes para que os territórios indígenas mereçam proteção ambiental elevada, sobretudo durante o licenciamento de empreendimentos de infraestrutura, que colocam em risco sua integridade.

No entanto, o caráter ambiental dos impactos não é o único elemento a ser considerado quando tratamos de povos indígenas afetados por hidrelétricas.

Numa perspectiva crítica, é preciso destacar que em 1981 Aspelin e Santos, com a obra Indian Áreas Threatened by Hydroelectric Projects in Brazil, alertavam para os riscos e prejuízos concretos

23 Disponível em: http://www.funai.gov.br/index.php/comunicacao/noticias/2914-terrasindigenas-apresentam-o-menor-indice-de-desmatamento-na-amazonia-legal?highlig $\mathrm{ht}=\mathrm{WyJwcm} 9 \mathrm{kZXMiXQ}==$ 
que diversos povos indígenas vivenciavam em consequência da implantação de hidrelétricas. A literatura sobre o tema ampliou-se rapidamente e o trato das questões sociais decorrentes da implantação de projetos hidrelétricos como "problema ambiental" foi bastante criticado, demonstrando-se objetivamente a inadequação desse tipo de discurso (SANTOS, 2007).

As hidrelétricas constituem drásticas intervenções nas condições de organização social indígena, podendo afetar aspectos culturais que os caracterizam como povos diversos. Por isso, os casos em que esses grupos se incluem no rol de comunidades potencialmente afetadas, impõem dois fatores de observância indispensável: a relevância do aspecto sociocultural dos impactos que podem ser produzidos, e a exigência de tratamento diferenciado em face dessa diversidade. Toda a ação do Estado nesse campo, seja ela normativa, executiva ou judiciária, deve atentar rigorosamente para esses fatores. Nesse sentido, o licenciamento desses empreendimentos não pode ter caráter exclusivamente ambiental, devendo ser socioambiental. A instauração de um processo específico para tratar questões sociais e culturais das populações indígenas do entorno, irá, certamente, reforçar a atuação de órgãos competentes por políticas dessa natureza, e contribuir para a especialização e qualificação das ações de cuidado com esses povos, equilibrando as preocupações ambientais, sociais e culturais na eventual implantação desses projetos.

\section{CONSIDERAÇÕES FINAIS}

O investimento em infra-estrutura para geração e transmissão de energia elétrica é crescente. Como vimos, a matriz energética no Brasil, funda-se amplamente na hidroeletricidade. Os debates e iniciativas referentes à concretização de projetos nesse sentido têm sido, frequentemente, vinculados à busca do crescimento econômico e à defesa de um projeto de desenvolvimento nele baseado.

O elemento econômico não pode, entretanto, ser a razão exclusiva a fundamentar um projeto de desenvolvimento, o qual deve 
pautar-se pela congregação de fatores e valores sociais, ambientais, culturais, humanos, etc.

Talvez seja impossível compatibilizar de maneira harmônica, crescimento econômico e direitos sociais e culturais. E se é possível superar esse desafio, é preciso dizer que, no mínimo, se está à frente de uma tarefa enorme e árdua. Na tentativa de conciliar benefícios da geração de energia, tais como incremento da produção e crescimento econômico, com o equilíbrio socioambiental, a vida e saúde da população, e a sobrevivência física e cultural dos diversos povos no Brasil, parece difícil defender apriorização absoluta das primeiras variáveis em detrimento da proteção da vida humana e da conservação da diversidade sociocultural e biodiversidade da Terra.

Entretanto, o direito, como regra, tem acompanhado e legitimado essa preponderância da razão econômica nos processos de eleição dos bens jurídicos a serem tutelados. A legislação que dispõe especificamente sobre o licenciamento de projetos e obras hidrelétricas desconsidera a diversidade sociocultural de comunidades que em boa parte dos casos, são ou serão afetadas de algum modo por essas intervenções. Em relação aos povos indígenas, como pretendemos demonstrar nesse artigo, o direito não é benéfico. As normas aqui tratadas e avaliadas, permitem afirmar que, a respeito do tema o ordenamento, quando dispõe acerca dessas populações, o faz de modo prejudicial a seus modos de viver e direitos.

Diante disso, é possível concluir pela necessidade de revisão das normas que foram aqui tratadas. Essa revisão precisa ser feita em razão e à luz da existência e presença de mais de trezentos diferentes povos indígenas no país, do dever de assegurar sua sobrevivência física e cultural, da importância da diversidade sociocultural no Brasil, e da necessidade de superação da monocultura social e jurídica. Concretamente, como fundamentos jurídicos para a revisão do ordenamento no que tange a esse tema, é possível recorrer especificamente a dispositivos da Constituição Federal e aos direitos fundamentais previstos na Convenção $n^{\circ} 169$ da OIT, conforme já defendido nesse trabalho. 
No que se refere ao tratamento das questões e conflitos relativos a esse assunto, é razoável, portanto, a busca de caminhos que operem fora da dicotomia entre um campo econômico e outro que abarca as razões social, cultural, e ambiental. Trata-se da necessidade de estabelecer novos espaços políticos de pactuação e cooperação no planejamento, implementação, e gestão de bens, recursos, e valores fundamentais a toda sociedade.

Os projetos e empreendimentos hidrelétricos, considerada a ordem de grandeza das intervenções que representam, a natureza e quantidade de recursos materiais que demandam, o grande número e diversidade de populações e setores sociais que envolvem e afetam, precisam estar inseridos na lógica desses novos espaços políticos de atução conjunta.

Apenas com o empreendimento de vontade política e boa-fé dentre os sujeitos sociais envolvidos nesses processos, será possível falar de um projeto de desenvolvimento social, cultural e ambientalmente sustentável que, sobretudo, não deixe de considerar os povos indígenas no Brasil.

\section{REFERÊNCIAS}

ANDRADE, Daniel Caixeta; ROMEIRO, Ademar Ribeiro. "Serviços ecossistêmicos e sua importância para o sistema econômico e o bem-estar humano" In: IE/UNICAMP. Campinas, fevereiro de 2009. Disponível em:file://C:/Users/User/Downloads/texto155\%20(2).pdf. Acesso em: 14/09/2015.

BANIWA, André Fernando. "O direito de consulta prévia dos povos indígenas no estado da república federativa do Brasil”. In:El derecho a la consulta previa de los pueblos indígenas en América Latina, Bolívia, Fundación Konrad Adenauer (KAS), 2012, p.43-77.

CANDAU, Vera Maria. "Direitos humanos, educação e interculturalidade: as tensões entre igualdade e diferença" In: Revista Brasileira de Educação On-line. Rio de Janeiro: PUC-Rio; n. 37, jan./abr. de 2008, p.45-185. 
COMISSÃO ECONCÔMICA PARA A AMÉRICA LATINA E O CARIBE (CEPAL). Avances en el último decenio y retos pendientes para la garantia de sus derechos: Documento elaborado pelo Centro Latinoamericano y Caribeño de Demografía (CELADE) - División de Población. Chile. 2014.

DUPRAT, Deborah. "A Convenção 169 da OIT e o direito à consulta prévia, livre e informada" In: RCJ - Revista Culturas Jurídicas. Vol. 1, Núm. 1, 2014, p. 51-72.

ESCOBAR, Arturo. Sentipensar con la tierra - Nuevas lecturas sobre desarrollo, territorio y diferencia.ed. Medellín: Ediciones Unaula, 2014.

MARTINEZ-ALIER, Joan. "The environmentalism of the poor" In:Geoforum. n.54,julho de 2014, p. 239-241.

PIOVESAN, Flávia. Direitos humanos e o direito constitucional internacional. 14. ed. São Paulo: Saraiva, 2013.

SANTOS, Boaventura de Sousa. "Direitos humanos: O desafio da interculturalidade" In: Revista Direitos Humanos, n. 2, junho de 2009, p. 10-18.

SANTOS, Sílvio Coelho dos. "Hidrelétricas e suas conseqüências socioambientais"In: VERDUM, Ricardo (org.) Integração, Usinas Hidrelétricas e Impactos Socioambientais. Brasil, INESC, 2007, p. 41-56.

VERDUM, Ricardo. "Obras de infra-estrutura no contexto da integração Sul-Americana” In: VERDUM, Ricardo (org.) Integração, Usinas Hidrelétricas e Impactos Socioambientais. Brasil, INESC, 2007, p. 13-40. 